\title{
Nutritional status and nutrient intake from complementary foods among breastfed children in Purworejo District, Central Java, Indonesia
}

\author{
Endang Dewi Lestari, MD, MPH; T Ninuk S Hartini, MS, PhD; \\ M Hakimi, MD, PhD; A Surjono, MD, PhD
}

\begin{abstract}
Background The growth rate of Indonesian infants beyond six months of age declines compared with that of the international reference population.

Objective This study aimed to describe the pattern of nutritional status among breastfed children and their intake of energy, protein, and zinc from complementary foods in Purworejo District, Central Java, Indonesia.

Methods The study was a cross sectional survey drawing breastfed children under 24 months old from a well-defined population. Children with a history of prematurity or low birth weight were excluded. Anthropometrical measurements were collected. Intake of complementary food was assessed using 24-hour recall. Analysis of nutritional intake was only performed in 11-23 month-old children.

Results Of 577 children enrolled, the prevalence of underweight, stunting, and wasting were $8.1 \%, 8.8 \%$, and $4.6 \%$, respectively. The prevalence of undernutrition increased with age. There was no association between frequency of breastfeeding during 24 hours in the second year of life and the nutritional status. The average intake of energy, protein, and zinc from complementary foods was very low i.e., $30 \%, 45 \%$, and $5 \%$ of the Indonesian recommended dietary allowance (RDA), respectively.

Conclusion The prevalence of undernutrition in breastfed children increases with age. The breastfed children beyond 11 months of age in Purworejo District need sufficient density of nutrients from complementary foods. [Paediatr Indones 2005;45:31-39].
\end{abstract}

Keywords: complementary food, breastfed children, undernutrition, nutritional status

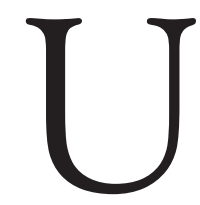

ndernutrition is a problem in many developing countries contributing to an estimated $54 \%$ of child deaths. ${ }^{1}$ The causes of undernutrition are complex and multifactorial; one of it is inadequate feeding. The main food of young children is breastmilk and complementary foods. Recently, an association between prolonged breastfeeding and malnutrition has been reported. The growth rate of breastfed infants declines after 6 months of age, ${ }^{2-4}$ and continuation of breastfeeding beyond 18 months old increases the risk of stunting. ${ }^{5}$ Further evidence reveals that undernourished children tend to be weaned older than other children. ${ }^{6}$ Thus, prolonged breastfeeding is a response to poor growth. ${ }^{7}$ However, faltering in growth is most evident during the age period in which complementary foods are given, which is probably inadequate. 8,9 Moreover, breastfed children tend to decrease their intake of breastmilk when given complementary foods. ${ }^{10}$

\footnotetext{
From the Department of Child Health, Medical School, Sebelas Maret Univesity, Surakarta, Indonesia.

Reprint requests to: Endang Dewi Lestari, MD, Department of Child Health, Medical School, Sebelas Maret University, Surakarta.

Tel. +62-271-731227, Fax. +62-271-664598, email: tarndang@yahoo.com

This article was presented on The $24^{\text {th }}$ International Congress of Pediatrics; 2004 Aug 17; Cancun, Mexico.
} 
According to UNICEF, 65\% of children in Indonesia are still breastfed at the age of 20-23 months. ${ }^{11}$ The prevalence of underweight, stunting, and wasting in children under five years of age are still relatively high, i.e., $34 \%$, $42 \%$, and $13 \%$, respectively. ${ }^{11}$ The $\mathrm{WHO}$ recommendation stated that the older the child, the more nutritious the complementary food should be. ${ }^{12}$ Generally, in developing countries, complementary foods are given insufficiently. ${ }^{13}$ The inadequate density of complementary foods may cause undernutrition in young children. There is also lack of information concerning how sufficient complementary foods should be for breastfed infants, qualitatively and quantitatively.

In Central Java, Indonesia, childhood malnutrition is a public health problem. Stunting reportedly affects $40 \%$ of under-five children. ${ }^{14}$ Breastfeeding is common and of long duration, but exclusive breastfeeding is rare and complementary foods, mostly plant-based, are introduced early. The plant-based diet contains little animal protein and low amounts of zinc, which places the infants at high risk of suffering from macro- and micronutrient deficiencies. ${ }^{15,16}$ This study aimed to determine the pattern of undernutrition in breastfed children and their intake of energy, protein, and zinc from complementary foods in Purworejo District, Central Java, Indonesia.

\section{Methods}

\section{Study design and eligibility criteria}

This was as a cross-sectional study carried out within a surveillance project of the Community Health and Nutrition Research Laboratories (CHN-RL) Gadjah Mada University. The study was conducted from September to December 1997 in Purworejo, an agricultural district in the southern part of Central Java.

Children aged less than two years who were breastfed in the period of the study were included. Children were excluded if they were born prematurely as defined by the mothers, had low birth weight, or had insufficient growth data.

\section{Sampling methods and sample size estimation}

A two-stage cluster sampling was done to obtain a sample of household representatives of the study area.
The sample size corresponded to approximately 10\% of the population. The sampling frame for the first stage consisted of approximately $20 \%$ of census enumeration areas of the 1990 census. The frame for the second stage was the list of households in each enumeraton area, as used in the 1993 agricultural census. The sample was proportionate to the size of each area.

Subjects were recruited through the surveillance system. They were classified into the following age groups: $0-1,2-3,4-5,6-8,9-11,12-17$, and 18-23 months. The classification was based on the protocol for the complementary feeding study i.e., types, composition, and consistency of foods usually consumed by each age group. Approximately 100 children for each group were randomly selected from each enumeration area (Figure 1).

\section{Data collection}

Subjects were visited every three months while data about vital statistics, demographics, and health were collected using a pre-coded questionnaire and a blank paper. Five trained field workers, all were high school graduates, interviewed the respondents (households). The following information was collected for each child, i.e., the identity of the child, anthropometric data (body weight and length), and 24-hour dietary recall for children aged more than 6 months.

\section{Anthropometric measurements}

Body weight was measured twice in naked condition, using a standard hanging Salter ${ }^{\circledR}$ Scale (UK) or a Seca ${ }^{\circledR}$ Digital Scale (Germany); its average rounded to the nearest $0.1 \mathrm{~kg}$. Body length was measured three times in recumbent position (crown to heel) using a local-made wood length-board with a rigid head board and a sliding foot-piece. The average of the three measurements, rounded to the nearest $0.1 \mathrm{~cm}$, was recorded. All equipments were standardized according to $\mathrm{WHO}$ recommendations. The measurements were conducted on the same day or at least within one week of the interview. The interview and anthropometric measurements were done at the respondent's house.

\section{Dietary analysis}

The 24-hour dietary recall was used to obtain information on dietary intake. Caregivers who fed 


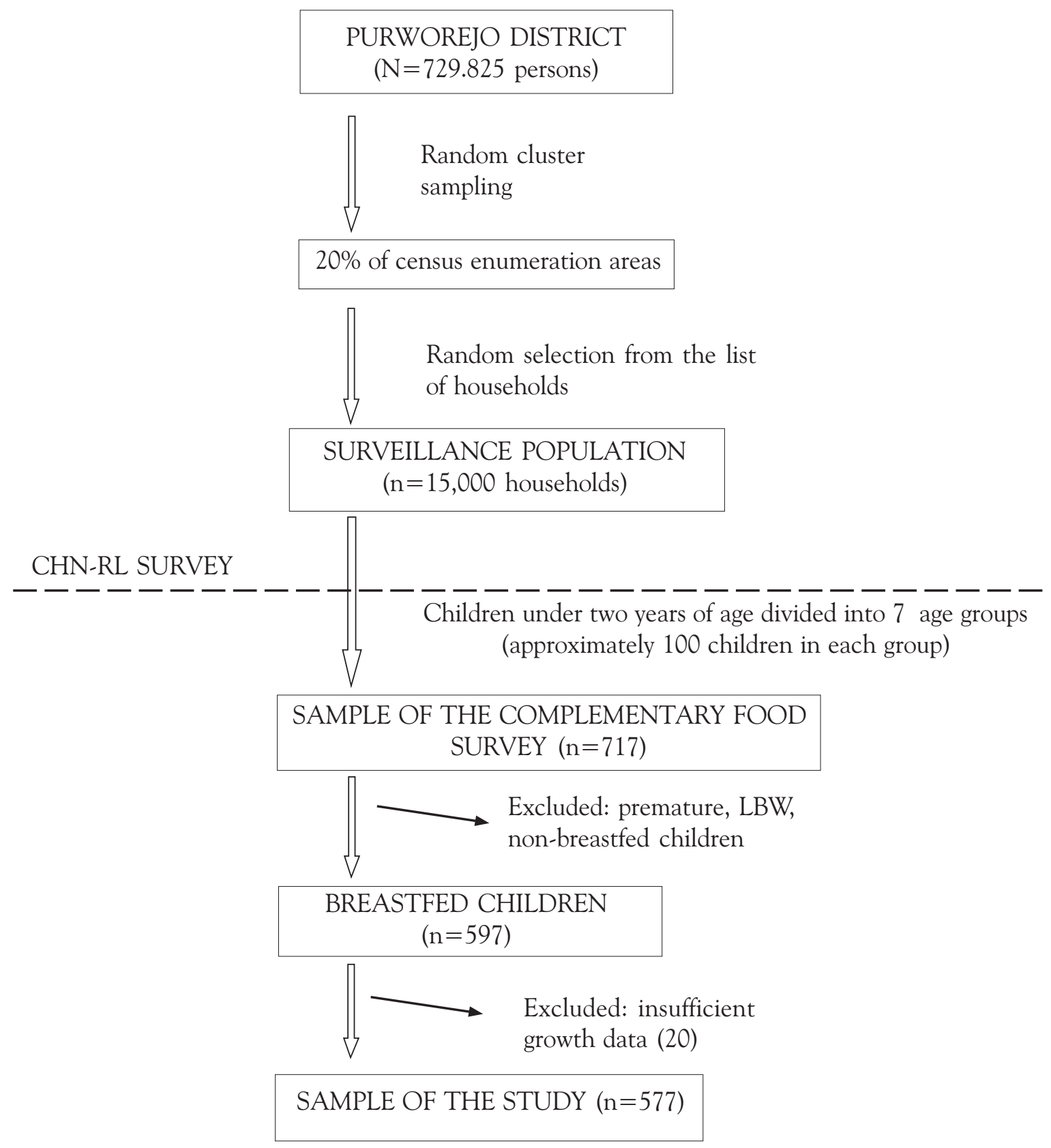

Figure 1. SAMPLING PROCESS

the child and/or prepared the food were interviewed to determine the amount of individual ingredients consumed from a homogenous recipe, the amount of each food item in the recipe, the total quantity of the recipe, and the amount of the recipe consumed. If the recipe was not homogenous, then the amount of each food item consumed was estimated separately. A set of common household measurements (cups, glasses, bowls, spoons, etc.) were used to estimate the amount of food items contained in a recipe and/ or consumed. A volumetric measurement was also used to estimate specific quantities, and a diet balance scale was used to estimate the amount of solid food items. If necessary, food models were used to assist recalls. In addition, one child from 
each age group greater than 6 months was observed on a second occasion (at least two days after the recall) to estimate intra-individual variability in nutrient intake. Since the second year of life brings the most inconsistent results in nutritional status, ${ }^{4,13}$ this analysis was only performed in children aged 11-23 months. The study was approved by the Ethics Committee of Gadjah Mada University, Yogyakarta, Indonesia.

\section{Data analysis}

Field supervisors monitored the quality and completeness of data. Ten percent of the households were randomly selected for spot-checking and rechecking of the data contents. Field supervisors also edited and cross-edited the questionnaires, and in case of incomplete data, also visited the households.

Nutritional status was expressed as z-score. It was also dichotomized into underweight and not underweight, stunted and not stunted, wasted and not wasted. The age groups were categorized into 0-5 months, 6-11 months, and 12-23 months. The frequency of breastfeeding was classified into 2 groups i.e., less than 8 times a day and 8 times or more a day. Parental education was categorized into education for 9 years or less and more than 9 years. Mother's occupation was categorized into housewife or working outside the house, while father's occupation was categorized into unemployed or employed.

Data were entered using dSurvey (dSurvey, a survey research system, 1989). Energy, protein, and zinc content of consumed foods were calculated using the International Minilist Database. Anthropometric indices (weight-for-age, heightfor-age, and weight-for-height) were converted to $z$-scores of the WHO-NCHS reference population using EPINUT (Epi Info 6, Center for Disease Control, USA).

Analyses were performed to determine the influence of age and sex on the outcome variables. Bivariate correlation was performed to see the association between the frequency of breastfeeding and nutritional status in the second year of life. The analyses were performed using Statistical Package for Social Science (SPSS) software version 9.0 for Windows.

\section{Results}

There were 717 children aged $0-23$ months randomly selected by age groups $(0-1,2-3,4-5,6-8,9-11,12$ $17,18-23$ months) from the surveillance. More children from the 0-5 month age group were selected compared to those from the 6-11 and 12-23 age groups. Children born prematurely, those with low birth weight, and those not breastfed were excluded, leaving 597 children. Another 20 children were excluded due to insufficient growth data.

\section{Baseline characteristics}

The baseline characteristics of the subjects and their parents are presented in Table 1. Mothers were mostly housewives (72.3\%), followed by farmers (14.0\%). The average age of mothers was 29.4 (SD 5.5) years.

\section{Anthropometrical status}

Anthropometrical status was stratified by age group and sex. The mean z-scores for weight-for-age, heightfor-age, weight-for-height of breastfed children decreased significantly by age $(p<0.05)$. There was no growth difference in terms of $z$-scores between boys and girls (Table 2). The lowest prevalence of undernutrition, defined either as underweight, stunted or wasted, was found in the youngest age group, and the prevalence increased with age (Table 3 ).

Table 3 depicts that the prevalence of underweight increased with increasing age, i.e., $1.0 \%$ in $0-5$ months of age, $4.8 \%$ in $6-11$ months of age, and $26.5 \%$ in $12-23$ months of age. A similar trend was also noted on the prevalence of stunted and wasted children.

There was no correlation between the frequency of breastfeeding in 24 hours during the second year of life and nutritional status, with rho Spearman's coefficient correlation of $-0.08,-0.05$, and -0.03 for weightfor-age, height-for-age, and weight-for-height, respectively (Figure 2).

\section{Complementary food in breastfed children aged 12-23 months}

Breastfed children aged 12-23 months had low intake of complementary food, however the 
Endang Dewi Lestari et al: Nutritional status and nutrient intake from complementary foods in breastfed children

Table 1. The baseline Characteristics of the subjects $(\mathrm{N}=577)$

\begin{tabular}{lll}
\hline \multicolumn{1}{c}{ Characteristics } & N & $\%$ \\
\hline Age & 275 & \\
$0-5$ months & 166 & 47.6 \\
$6-11$ months & 136 & 28.8 \\
$12-23$ months & & \\
Sex & 276 & 47.8 \\
Male & 301 & 52.2 \\
Female & & \\
Growth status & 47 & 8.1 \\
Underweight (W/A <-2SD) & 51 & 8.8 \\
Stunted (H/A <-2SD) & 27 & 4.6 \\
Wasted (W/H <-2SD) & & \\
Frequency of breastfeeding & 50 & 8.7 \\
Less than 8 times a day & & \\
Parents' formal education & 213 & 36.9 \\
Mother's education $>9$ years & 364 & 27.1 \\
Mother's education $<9$ years & 156 & 73.0 \\
Father's education $>9$ years & 421 & 72.3 \\
Father's education $<9$ years & & 27.7 \\
Mother's occupation & 417 & \\
Housewife & 160 & \\
Working outside the house & &
\end{tabular}

TABLE 2. MEAN Z-SCORE FOR WEIGHT-FOR-AGE, HEIGHT-FOR-AGE, AND WEIGHT-FOR-HEIGHT BY AGE GROUPS AND SEX

\begin{tabular}{llll}
\hline Variable & WAZ & HAZ & WHZ \\
\hline \multicolumn{1}{l}{ Age group* } & Mean (SD) & Mean (SD) & Mean (SD) \\
0-5 months & $0.2(1.0)$ & $0.1(1.1)$ & $-0.1(1.0)$ \\
6-11 months & $-0.6(1.0)$ & $-0.4(1.1)$ & $-0.4(1.1)$ \\
12-23 months & $-1.5(0.8)$ & $-1.3(1.1)$ & $-0.9(1.0)$ \\
Sex & & & \\
Male & $-0.4(1.2)$ & $-0.3(1.3)$ & $-0.3(1.1)$ \\
Female & $-0.5(1.1)$ & $-0.4(1.2)$ & $-0.3(1.0)$ \\
& & &
\end{tabular}

WAZ: weight-for-age * ANOVA for difference between age groups, $p<0.05$ HAZ: height-for-age ${ }^{* *}$ ANOVA for difference between sexes, $p>0.05$ WHZ: weight-for-height

Table 3. Prevalence of undernutrition in breastfed Children by age group

\begin{tabular}{lccrrrr}
\hline Age & \multicolumn{2}{c}{ Underweight $(\mathbf{n = 4 7 )}$} & \multicolumn{2}{c}{ Stunted $(\mathbf{n}=\mathbf{5 1})$} & \multicolumn{2}{c}{ Wasted $\mathbf{( n = 2 7 )}$} \\
\hline & $\mathbf{N}$ & $\%$ & $\mathbf{N}$ & $\%$ & $\mathbf{n}$ & $\%$ \\
\hline 0-5 months & 3 & 1.0 & 6 & 2.2 & 5 & 1.8 \\
6-11 months & 8 & 4.8 & 10 & 6.0 & 9 & 5.4 \\
12-23 months & 36 & 26.5 & 35 & 25.7 & 13 & 9.6 \\
\hline
\end{tabular}

calculation did not include the amount of nutrient intake from breastmilk. The average energy intake from complementary food was less than $50 \%$ of the Indonesian recommended dietary allowance (RDA), and zinc intake was less than $10 \%$ of RDA, while protein intake of complementary food was approximately $50 \%$ of
RDA. The nutrient intake data was highly skewed (Table 4).

Median values were presented to estimate the central tendency of the complementary food. There was no information about missing data regarding food intake. The average complementary food intake in undernourished children (underweight, 


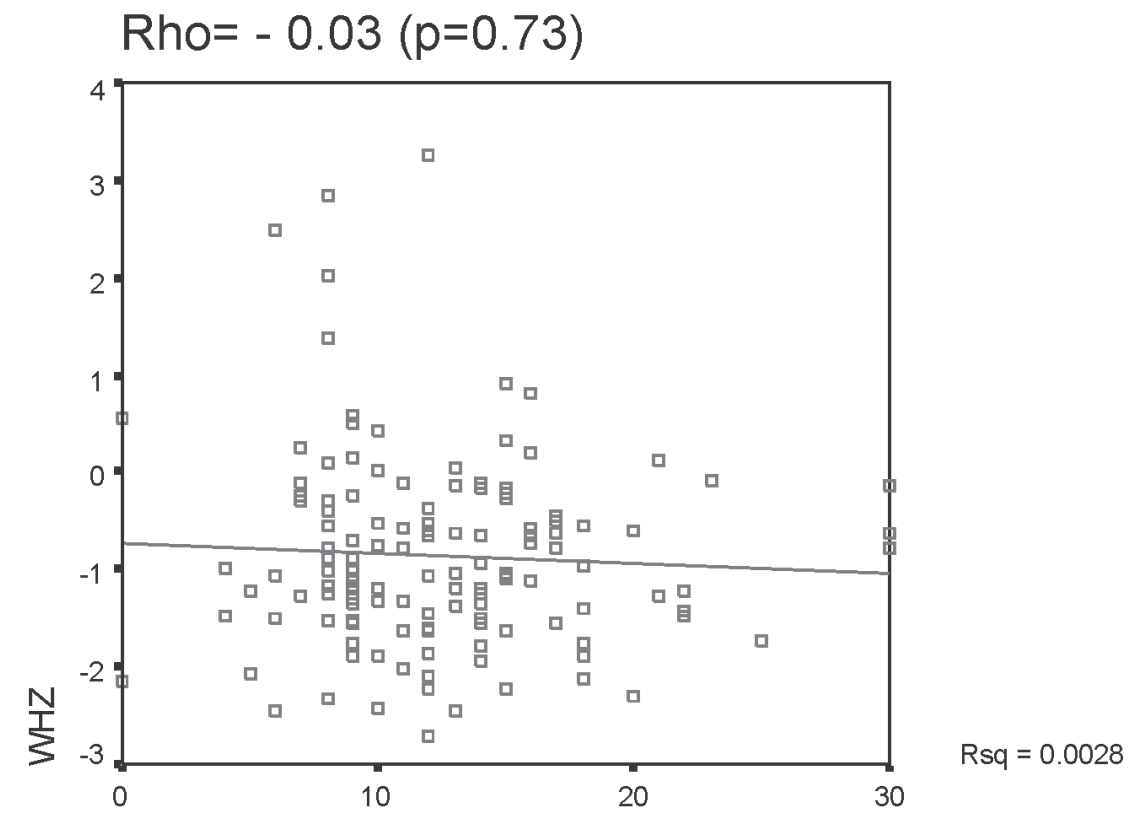

\section{FREQUENCY OF BREASTFEEDING DURING 24 HOURS}

Figure 2. Bivariate correlation between nUtritional status (Weight for HEIGHT) AND FREQUENCY OF BREASTFEEDING IN BREASTFED CHILDREN AGED 1223 MONTHS $(\mathrm{N}=136)$

stunted, and wasted) was lower than that of wellnourished ones (Table 5), although it was not statistically significant.

\section{Discussion}

Several limitations of this study should be noted. The study sample was a sub-sample of the main study of complementary feeding in children under two years old conducted by CHN-RL. Of the 717 children in the sample study, we used 577 children after excluding non-breastfed, premature, low birth weight, and those with insufficient growth data. After deciding to use a cluster random sampling, the number of subjects in each group of study sample was estimated to be 100 children. This estimation brought the distribution of children's age to be unequal; more children under six months of age were selected. The small sample size decreased the precision of the study.

Due to the cross sectional nature, we only collected dietary information once. Taking dietary history using the 24-hour recall method is simple, but a single measurement of feeding may associate poorly with the true dietary history of the child until the age of the interview. However, these limitations are compensated by several advantages of the CHN-RL surveillance system. The ages of children were known with precision. Also the anthropometric measurement and the 24-hour dietary recall were collected in a reproducible way.

The prevalence of underweight, stunting, and wasting in breastfed children below 24 months of age is lower compared to that of undernutrition in under five year olds from the same area reported by the Ministry of Health in 1999 i.e., $28 \%, 32 \%$, and 10\%, respectively. ${ }^{17}$ The difference in prevalence is probably related to the fact that more undernourished children came from both breastfed and more non-breastfed children of under five years. It is probably due to breastfeeding which protects these children from suffering undernutrition. ${ }^{18}$ Another possibility could be that they were fed inadequately in quantity and quality of the foods. This study also shows the prevalence of breastfed children which increases with age. This pattern is similar to the pattern of growth in breastfed 
Endang Dewi Lestari et al: Nutritional status and nutrient intake from complementary foods in breastfed children

Table 4. Calculated intake of energy, protein, and zinc from 24-hour dietary recall in BREASTFED CHILDREN AGED 12-23 MONTHS $(\mathrm{N}=136)^{*}$

\begin{tabular}{lrrrrrr}
\hline & \multicolumn{2}{c}{ Energy (\% of RDA) } & \multicolumn{2}{c}{ Protein (\% of RDA) } & \multicolumn{2}{c}{ Zinc (\% of RDA) } \\
\hline & Kcal & \% RDA & G & \% RDA & Mg & \% RDA \\
\hline Mean & 514.95 & 41.20 & 15.47 & 67.27 & 1.77 & 7.69 \\
Standard Deviation & 421.27 & 23.60 & 15.62 & 67.90 & 1.88 & 8.16 \\
Median & 374.00 & 29.92 & 10.40 & 45.22 & 1.11 & 4.83 \\
Minimum & 20.00 & 1.60 & 0.30 & 1.30 & 0.00 & 0.00 \\
Maximum & 2600.0 & 208.00 & 93.40 & 406.09 & 11.30 & 49.13 \\
\hline
\end{tabular}

${ }^{*}$ Missing data $=5$

Table 5. Median intake of energy, protein and Zinc from 24-hour dietary reCall in BREAstfed CHILDREN 12-23 MONTHS OF AGE STRATIFIED BY NUTRITIONAL STATUS

\begin{tabular}{lcccccc}
\hline & \multicolumn{2}{c}{ Underweight } & \multicolumn{2}{c}{ Stunted } & \multicolumn{2}{c}{ Wasted } \\
\hline & Yes $(\mathrm{n}=32)$ & No $(\mathrm{n}=94)$ & Yes $(\mathrm{n}=29)$ & No $(\mathrm{n}=97)$ & Yes $(\mathrm{n}=9)$ & No $(\mathrm{n}=117)$ \\
\hline Energy (kcal) & 301.50 & 379.00 & 328.00 & 383.00 & 372.00 & 503.00 \\
Protein (g) & 40.43 & 46.96 & 43.26 & 47.39 & 44.35 & 45.65 \\
Zinc (m) & 3.96 & 5.13 & 4 & 5.13 & 4.48 & 4.85 \\
\hline
\end{tabular}

children in other studies. ${ }^{2,3,19}$ These studies emphasized that it was not breastfeeding per se which caused the growth faltering in prolonged breastfed children, rather that malnourished children were breastfed longer than their non-malnourished peers. ${ }^{7,20}$ Moreover, this study also reveals that there was no correlation between the frequency of breast-feeding and the nutritional status of the children over one year of age. The possible explanation is that breastfeeding is not the main cause of the undernutrition. Breastfeeding alone is not enough to satisfy the physiological requirement to maintain the growth of the child, adequate nutritious complementary food must be added in older children. ${ }^{19}$ Poor complementary feeding among breastfed children is an important risk factor for malnutrition, ${ }^{21}$ the density of the complementary foods are also an important role. The study demonstrates that the average intake of complementary food in children 12-23 months of age were below the Indonesian RDA. For children beyond 11 months of age, complementary foods have an important role in supplementing nutrients provided through the breastmilk. The proportion of energy intake of complementary food should be larger than that of breastmilk at that age. ${ }^{23}$ Lack of nutrient intake from complementary food will have an obvious impact on the growth of children beyond 11 months of age.

In general, breastmilk consumption and energy intake from breastmilk decreases after 8 months of age.
However, regardless of the quantity of breastmilk intake, we find evidence that the intake of complementary foods in children beyond 11 months of age was very low compared to the RDA. In the following discussion, we describe the rough calculation of specific nutrient intake consumed by the children beyond 11 months of age. As WHO used the amount of nutrient intake from breastmilk to define the requirement of nutrient intake from complementary foods at different ages, ${ }^{13}$ this following calculation also uses the reference of nutrient intake from breastmilk to estimate the total amount of nutrient intake of children beyond 11 months in this population. What is already known is that energy intake from breastmilk is on average between 300 and $350 \mathrm{kcal} / \mathrm{d}$ at $11-23$ months. ${ }^{23}$ To meet energy requirements, the estimated energy need from complementary foods is at least $750 \mathrm{kcal} / \mathrm{d}$ at $12-23$ months, depending on the amount of breastmilk consumed. ${ }^{23}$ A previous study conducted in the same area implied that the average energy intake from breastmilk in children $12-23$ months of age was $397 \mathrm{kcal} / \mathrm{d} .{ }^{15} \mathrm{Ac}$ cording to the Indonesian RDA, the need of energy intake in children aged $11-23$ months is $1250 \mathrm{kcal} / \mathrm{d} .{ }^{24}$ Assuming that the energy intake from breastmilk is 350 $\mathrm{kcal} / \mathrm{d}$ and the median energy intake from complementary foods is $374 \mathrm{kcal} / \mathrm{d}$ giving a median total energy intake of some $724 \mathrm{kcal} / \mathrm{d}$, the children in our study have energy consumption below $60 \%$ of the Indonesian RDA. Also, according to the Indonesian RDA, 
the necessary protein intake in children $12-23$ months of age is $23 \mathrm{~g} / \mathrm{d},{ }^{24}$ whereas the previous study in the same area mentioned that the children 12-23 months of age received $5.7 \mathrm{~g}$ protein per day from breastmilk. ${ }^{15}$ Assuming that the protein intake from breastmilk is $5.7 \mathrm{~g} / \mathrm{d}$ and the median protein intake from complementary foods is $10 \mathrm{~g} / \mathrm{d}$ giving a total protein intake of $16 \mathrm{~g} / \mathrm{d}$, the children in our study had protein consumption below $70 \%$ of the Indonesian RDA. The necessary zinc intake per day for children 12-23 months of age is $10 \mathrm{mg} / \mathrm{d} .{ }^{24}$ From breastmilk, the child $12-23$ months of age is able to obtain an average of $0.76 \mathrm{mg} /$ d. ${ }^{15}$ Assuming that the zinc intake from breastmilk is $0.76 \mathrm{mg} / \mathrm{d}$ and the median zinc intake from complementary foods is $1.11 \mathrm{mg} / \mathrm{d}$ giving a total zinc intake of about $2 \mathrm{mg} / \mathrm{d}$, the children in our study had zinc consumption below $20 \%$ of the Indonesian RDA.

The number of children who were breastfed less than eight times per day was low (8.7\%) and the frequency of breastfeeding in the second year of life had no association with the nutritional status. But it should be noted that the study did not assess the children's effectiveness in sucking the breast. Hence, the possibility of sucking ineffectively among children beyond a year of age is still a factor that may influence the total amount of their nutrient intake. Nevertheless, even though the study did not assess the total amount of breastmilk intake, it is suggested that the problem should be focused on how well the complementary foods are given in breastfed children. Unfortunately, we used a simple design in our study, thus we have limitations on the recall of dietary history. One dietary recall does not reflect the real history of the of the child's complete feeding. It probably will reflect the real history of the feeding pattern if dietary recall is followed using longitudinal study. At any rate, the rough pattern of complimentary feeding can be used as a baseline figure describing complementary feeding in Purworejo. The average nutrient intake from complementary foods of children with undernutrition in this study was lower than that of nutrient intake in children without undernutrition. Thus, in order to obtain normal growth, children in this study area should be fed more nutritious foods.

Another result of this study shows that the prevalence of underweight and stunting in children 12-23 months old was higher than the prevalence of wasting at the same age, indicating that these children suffered from a more chronic state of undernutrition. In this population an increase in the prevalence of stunting may indicate poor socioeconomic condition. ${ }^{22}$ It is probably due to the feeding practice using lower density complementary foods in Purworejo District which occurred for a long period of time. This represents a public health problem which deserves attention. Improving the socioeconomic conditions will influence the feeding practice in that population. Programs that prevent malnutrition and multi-sectoral collaboration should be addressed in order to improve the child health condition.

In summary, this study shows that breastfed children children at the age of 12-23 months were most likely to develop undernutrition compared to those $<12$ mo. In those $12-23$ mo children there is no association between frequency of breastfeeding and nutritional status. However, this study did not assess how effective the children suck the breast. It may influence the total amount of nutrient intake. Moreover, the intake of complementary foods in the second year of life of the study subjects was below the Indonesian RDA, hence, in order to prevent growth retardation, promotion of nutritious and high density complementary foods should also be emphasized as well as breast-feeding, especially in children 12-23 months of age. The importance of adequate complementary feeding in the second year of life needs to be stressed in nutrition education programs. The intervention should focus on counseling the mothers which should be done each time a mother visits a health care system. Integrated Management of Childhood Illness (IMCI) may present a good way to achieve this; aside from guiding the management of ill children, it also covers how to counsel mothers on feeding problems in children. ${ }^{1}$

\section{Acknowledgments}

A special thank goes to Hans Stenlund, $\mathrm{PhD}$ and Torbjorn Lind, MD, PhD from the Epidemiology Department of Public Health and Clinical Medicine, Umea University for their comments in giving biostatistic and scientific inputs. We remember also Tunjung Wibowo, MD; Fadjar and Eko who contributed in collecting and supporting the data for this study. 
Endang Dewi Lestari et al: Nutritional status and nutrient intake from complementary foods in breastfed children

\section{References}

1. WHO. Integrated Management of Childhood Illness (IMCI). 2001. http://www.who.int/child-adolescenthealth/integr.htm

2. Victoria CG, Morris SS, Barros FC, de Onis M. The NCHS reference and the growth of breast- and bottlefed infants. J Nutr 1998;128:1134-8.

3. Dewey KG, Heinig MJ, Nommsen LA, Peerson JM, Lonnerdal B. Growth of breastfed and formula-fed infants from 0-18 months: The DARLING study. Pediatrics 1992;89:1035-41.

4. Julia M, Surjono A, Hakimi M. Role of breastfeeding in protecting children from malnutrition: A comparative study of nutritional status in children under two years of age in two districts in Indonesia. Paediatr Indones 2002;42:106-12.

5. Kikafunda JK, Walker AF, Collett D, Tumwine JK. Risk factors for early childhood malnutrition in Uganda. Pediatrics 1998;102:1-8.

6. Simondon KB, Simondon F. Mothers prolong breastfeeding of undernourished children in rural Senegal. Int J Epidemiol 1998;27:490-4.

7. Simondon KB, Costes R, Valerie D, Diallo A, Simondon F. Children's height, health and appetite influence mothers' weaning decisions in rural Senegal. Int J Epidemiol 2001;30,476-81.

8. Brown $\mathrm{KH}$, Begin F. Malnutrition among weanings of developing countries: still a problem begging for solutions. J Pediatr Gastroenterol Nutr 1993;17:132-8.

9. Adair LS, Guilkey DK. Age-specific determinants of stunting in Filipino children. J Nutr 1997;127:314-20.

10. Hornell A, Hofvander Y, Kylberg E. Association with pattern and duration of breastfeeding. Pediatrics 2001;107:1-7.

11. Unicef. The state of the World's Children 2001. http:/ /www.unicef.org

12. WHO. Feeding young children. http://www.who.int/ publications/newslet/9/feeding_young_children.htm
13. WHO. Complementary feeding of young children in developing countries: a review of current scientific knowledge. WHO/NUT/98.1.p.17-9.

14. Kolsteren PW. Growth faltering in Madura, Indonesia: a comparison with the NCHS reference and data from Kasongo, Zaire. Ann Trop Paediatr 1996;16:233-42.

15. Ninuk TSH, Dibley MJ, Sadjimin T, Serdula M. Food and nutrient intakes of infants and young children in Central Java, Indonesia. Yogyakarta, Indonesia: Clinical Epidemiology and Biostatistics Unit, University of Gadjah Mada, 1997.

16. Lind T, Lönnerdal B, Stenlund H, Ismail D, Seswandhana R, Ekström EC, and Persson LA. A community-based randomized controlled trial of iron and zinc supplementation in Indonesian infants: interactions between iron and zinc. Am J Clin Nutr 2003;77:883-90.

17. Profil Kesehatan Purworejo [Purworejo Health Profile] 1999.

18. Vilalpando S, Alarcon ML. Gowth faltering is prevented by breast-feeding in underprivileged infants from Mexico City. J Nutr 2000;130:546-52.

19. Simondon KB, Simondon F. Prolonged breastfeeding and malnutrition. Int J Epidemiol 1997,26:677-84.

20. Marquis GS, Habicht JP, Lanata CF, Black RE, Rasmussen KM. Association of breastfeeding and stunting in Peruvian Toddlers: An example of reverse causality. Int J Epidemiol 1997;26:349-56.

21. Ricci JA, Becker S. Risk factors for wasting and stunting among children in Metro Cebu, Philippines. Am J Clin Nutr 1996; 63: 966-75.

22. WHO Expert Committee. Physical status: the use and interpretation of anthropometry. WHO. Geneva; 1995. p. 161-255.

23. Dewey KG. Complementary feeding and breastfeeding. Pediatrics 2000; 106(5):1301.

24. Muhilal, Djalal F, Hardinsyah. Angka kecukupan gizi yang dianjurkan. Widya Karya Pangan dan Gizi, Jakarta 1998. 